\title{
Research of Loadings Character in Electrical Networks of Open-Casts Mining
}

\author{
Alla Zaharova ${ }^{1}$, Irina Lobur ${ }^{1, *}$, and Nadezda Shauleva ${ }^{1}$ \\ ${ }^{1}$ T. F. Gorbachev Kuzbass State Technical University, Department Electric drive and automation, \\ 650000, Kemerovo, the Russian Federation
}

\begin{abstract}
Calculation of loadings and losses in electrical networks of open-casts is bound to the difficulties caused by irregularity of individual production schedules of rope shovels - the main and most power-intensive consumers. The computational method according to load charts is presented. It allows to consider irregularity of loading manifestation during an shovelling cycle that significantly increases accuracy of calculations of losses in net-works in comparison with calculation for mean squared current.
\end{abstract}

\section{Introduction}

All rope shovels - shovel loaders and draglines - have the common regularity of a power consumption - clear presented recurrence that caused by the sequence of the operations which are carried out by machines in technological process. For this reason it is expedient to consider formation of loading of the individual machine during a production cycle when each operation - cutting, raising of a hoe with load, the turn and unloading - are characterized by the level and character of power consumption. Such way is spoken well by differences between individual and group production schedules of rope shovels.

\section{Loadings of rope shovels}

Overseeing by character of power consumption on the connections departing from electric power substations and on inputs of electric power substations on Kedrovsky and Chernigovsky open casts in Kuzbass showed difference in the nature of formation of loading individual rope shovel and their group, being powered from one connection. It is established that the type of a casual process' distribution function of loading by group of rope shovels is defined by probability of theirs personal work which depends on process consideration duration $[1-3,9,10]$. The probability of work 1 of independent receivers from their total number $\mathrm{n}$ can be estimated according to the binomial distribution law. In practice the interest is the probability of value of the common loading of the switched-on consumers. Measurements showed that in the presence of two rope shovels are powered from one connection, the distribution of the common loading strives for the normal law for

\footnotetext{
* Corresponding author: 1oburia@kuzstu.ru
} 
which characteristic it is enough to know an mathematical expectation and a mean squared deviation $[4,5,8,11]$.

When calculating losses of the electric power it is convenient to operate not with value of the common load of rope shovels group powered from one line, but load of each of them separately. The faithful representation of the loading formation nature is given by its chart during an excavation cycle.

For definition of a look and distribution parameters the recorded loading diagrams of shovel loaders (fig. 1) and the draglines (fig. 2) working in various conditions were studied. For each cycle duration of a cycle and pause and number of loading peaks of different levels during $10 \mathrm{sec}$. were determined by charts.

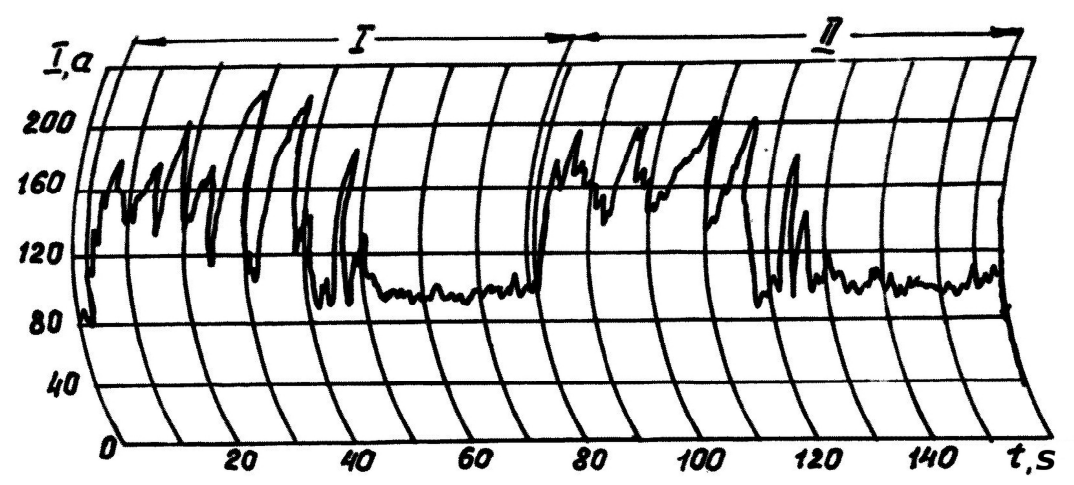

Fig.1. Chart of 1 rope shovel loadings EKG-8.

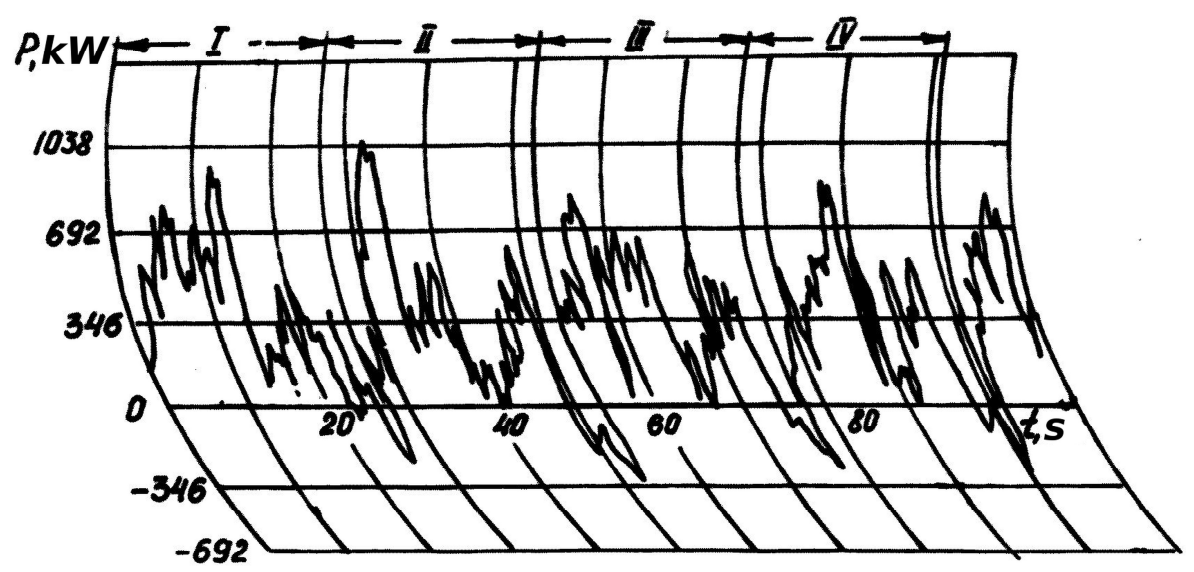

Fig.2. Chart of 1 rope shovel loadings ESh-14/60.

According to these data the histograms of loading shown in fig. 3, 4 were drawn. It is possible to present these histograms in the form compositions of two distribution laws - the uniform and exponential which polygons, respectively, are OABD and LMNB. CHAST of distribution Part of distribution of CDEK represents the improbable values of loading peaks having no more than $7,5 \%$.

Such representation is possible on condition that loading of each level is formed independent of loading of other levels, that is independent random values work. The common density distribution of loading has a form $[6,7]$

$$
f\left(P_{o}\right)=f\left(P_{p}\right) f\left(P_{e}\right),
$$


where $P_{p}$ and $P_{e}$ - symbols of the loadings having, respectively, the uniform and exponential distributions.

Having taken into consideration that minimum loading corresponds to a no-load operation of the rope shovel engine $P_{x}$, and maximal $-P_{m}$ (fig. 3,4), we will receive density of the uniform

$$
f\left(P_{p}\right)=\frac{1}{P_{m}-P_{x}}
$$

and exponential distributions

$$
f\left(P_{e}\right)=\frac{1}{P_{c}} \exp (-P / P c)
$$

where $P_{c}$-average loading for its exponential distributed part.

Common density distribution

$$
f\left(P_{0}\right)=\frac{1}{P_{m}-P_{x}} \int_{P_{x}}^{P_{m}} \frac{1}{P_{c}} \exp \left(-P / P_{c}\right) d P .
$$

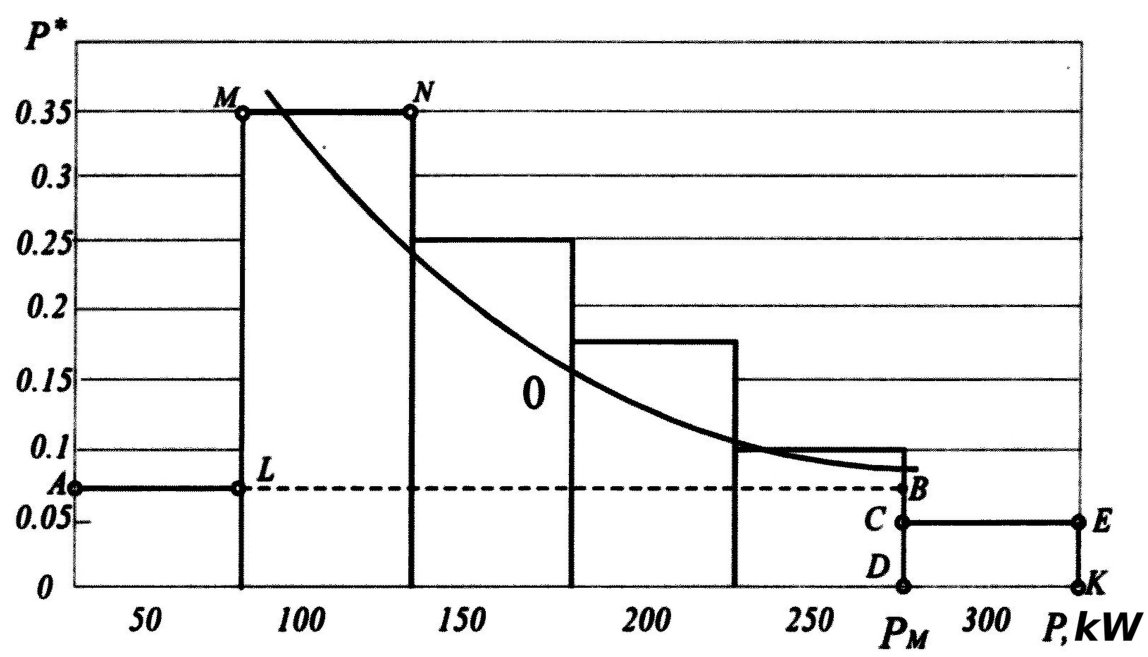

Fig.3. Histograms of distribution of power in one cycle shoveling EKG-8 


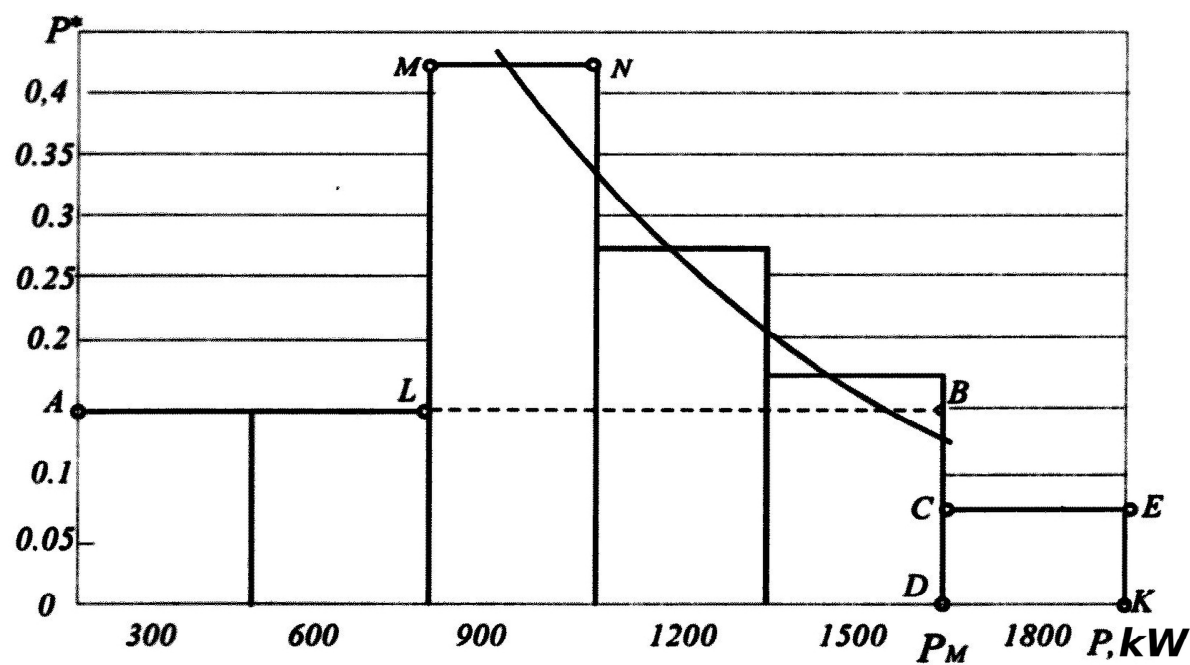

Fig.4. Histograms of distribution of power in one cycle shoveling ESh-14/60

It is convenient to solve a problem of distribution laws by means of the method of characteristic functions, using formula

$$
G(P)=\int_{-\infty}^{\infty} e^{j P\left(P_{c}\right)} f(P) d P,
$$

as characteristic function for composition of random values is equal to product their characteristic functions.

For the exponential distribution law the characteristic function looks as follows

$$
G_{p_{e}}(P)=\left(1 / P_{e}\right) e^{j P P_{x}} /\left[\left(1 / P_{e}\right)-j P\right]
$$

For the uniform distribution law the characteristic function will be defined as

$$
G_{P_{p}}(P)=\left(e^{j P P_{m}}-e^{j P P_{x}}\right) /\left[j P\left(P_{m}-P x\right)\right] .
$$

As a result we receive the characteristic function for set of distributions laws in a look

$$
\begin{aligned}
& G_{o, c}(P)=G_{p, p}(P) G_{p, e}(P)= \\
& =\left(1 / P_{e}\right)\left(e^{j P\left(P_{m}+P_{x}\right)}-e^{2 j P P_{x}}\right) /\left\{\left[j\left(P_{m}-P_{x}\right)\right]\left[\left(1 / P_{e}\right)-j P\right] P\right\} .
\end{aligned}
$$

Mean value is on a formula

$$
P_{o, c}=M[P]=-G^{\prime}(0) \text {. }
$$

As a result of derivation and a passage to the limit $P \rightarrow 0$, we receive expression for the common average of composition of two distribution laws

$$
P_{o, c}=\left\lfloor 0,5 P_{m}^{2}-1,5 P_{m} P_{x}-5,5 P_{x}^{2}-\left(1 / P_{e}\right) \mid /\left(P_{m}-P_{x}\right) .\right.
$$


The explained approach gives a qualitative picture. For receiving the quantitative assessment it is convenient to proceed from rated power of the rope shovel engine:

$$
P_{c}=P_{n} k_{i}
$$

where $k_{i}$ - the capacity factor equal 0,83 - 0,85 for rope shovels - shovel loaders and 0,87 0,89 - for draglines.

In the received expression the part of loading represented on histograms by DCEK rectangle is not considered. It is convenient to present this part of the chart in the form of casual emissions of loading for some fixed $P_{m}$ level. It is apparent that casual process of emissions both in time, and in size is not the continuous. For its characteristic it is possible to use a median number of emissions $N_{B}$ for a calculated time slice, average duration $\tau_{B . c p}$ and average amplitude $A_{B . c p}$. At rather high level $P_{m}$ of casual process concerning which emissions are defined the probability of their emergence has Puasson's distribution with the $a=1$ parameter during $10 \mathrm{sec}$. The main difficulty of emissions characteristics' calculation is need to express them through characteristics of initial process as statistical information on emissions in practice is absent.

Let's enter assumption about existence of a stable process which is characterized by distribution laws and correlative functions. Correlative function of process $K(\tau)$ at $\tau=0$ is equal to dispersion of process $D(P)$, and at $\tau \geq 1$ can characterize crossings number of realization of fixed level $P_{m}$ process:

$$
P_{m}=P_{c}+\beta \sigma_{p}
$$

where $\beta$ - the frequency rate of a mean squared deviation of casual process depending on probability of excess by ordinates of the calculation level process $P_{m} ; \sigma_{p}$ - a mean squared deviation of power.

The power determined by a ratio (2) is the horsepower rating consumed by the rope shovel without emissions. The $\beta$ and $\sigma_{p}$ values in relation to rated power of rope shovel engines $P_{n}$ received on the basis of calculation of their loadings for charts are given in the table.

Table 1. Calculated coefficients $\beta$ and $\sigma_{p}$.

\begin{tabular}{|l|l|l|}
\hline Rope shovel type & $\beta$ & $\sigma_{p}$ \\
\hline Shovel loaders & 1,09 & $0,11 P_{n}$ \\
\hline Draglines & $1,1-1,12$ & $0,09 P_{n}$ \\
\hline
\end{tabular}

Taking into account $\beta$ and $\sigma_{p}$ values from tab. 1, the ratio (2) will take the following form:

for draglines

$$
P_{m l}=P_{c}+0,09 \beta P_{n l ;}
$$

for shovel loaders

$$
P_{m 2}=P_{c}+0,11 \beta P_{n 2}
$$

In $[6,7]$ it is shown that the number of emissions of power out of limits $P_{m}$ is determined by value of the fixed correlative function, value of integral function of distribution of ordinates of process at $P=P_{m}$ and frequency rate of a mean squared deviation $\beta$. Researches of charts of loadings showed that correlative function fades from time constant $\tau=10 \mathrm{sec}$., and duration of emissions having the exponential nature of distribution 
and mean value 7 - 12 sec., cannot render crucial importance on heating of conductors of a feed line and can not be considered. The main impact on losses in a power line is exerted by the power determined taking into account irregularity of loading manifestation during an excavation cycle.

The current $I_{m}$ received by means of formulas of equations' set (3) allows to consider more precisely the actual losses in electrical networks. Calculations showed that accuracy of accounting of losses increases in comparison with the standard method on the basis of mean squared current by $23-27 \%$.

\section{Conclusions}

1. Loading of the individual rope shovel in one shot of excavation is characterized by composition of the uniform and exponential distributions.

2. Horsepower rating of the rope shovel exceeds its mean value owing to irregularity of loading for an excavation cycle.

Use of the horsepower rating considering irregularity of loading of the excavator for an excavation cycle increases accuracy of calculations of losses in networks in comparison with calculation for mean squared current for $23-27 \%$.

We express gratitude to Razgildeev Gennady Innokentyevich (RIP), the Doctor of Engineering, professor, the academician of the Russian Academy of Natural Sciences, the academician of RIA; to the honored science and engineering figure of the Russian Federation, the expert in the field of reliability, safety and profitability of electric equipment and systems of power supply of the mining enterprises for the help in work process in research of problems of power consumption modeling in Kuzbass open-casts mining.

\section{References}

1. A. I. Shushukin, Power plants: reliability, efficiency, energy saving (GCE-Energy, Moscow, 2008)

2. G.G. Pivnyak, Mining journal, 7, 3 (2004)

3. The Outlook for energy in the world and Russia to the year 2040 (ERI RAS, Moscow, 2014)

4. V. M. Goikhman, U. P. Minovsky, The method of determining the actual values of the key parameters of energy consumption used in the calculations for the electric power in the coal industry (IGD, Moscow, 1981)

5. B. I. Kudrin, Industrial energy, 6, 33 (2000)

6. L. Zags, Statistical estimation (Statistics, Moscow, 1976)

7. O. N. Kassandrova, V. V. Lebedev, The processing of observational data (Science Publishers, Moscow, 1970)

8. B. P. Belih, I. S. Sverdel, V. K. Oleinikov, Electric load and consumption by mining enterprises (Nedra Publishers, Moscow, 1971)

9. V. K. Oleinikov, Analysis and planning of energy consumption on the mountain predprijatiakh (Nedra Publishers, Moscow, 1983)

10. A.G. Zakharova, G.I. Razgildeev, Journal of Coal, 7, 48 (2000)

11. A.G. Zakharova, I.A. Lobur, N.M. Shauleva, V.A. Borovtsov, Kemerovo (Atlantis Press, Paris, 2016) 